\title{
Client, Employer and Employee: Mapping a complex triangulation
}

Christelle Havard, Associate Professor in Human Resource Management, Ecole Supérieure de Commerce de Dijon, France

Brigitte Rorive, Internal consultant, Hopitaux Universitaires de Genève, Switzerland

André Sobczak, Associate Professor at Audencia Nantes School of Management, Director of Audencia's Centre for Global Responsibility, Audencia Nantes Ecole de Management, France

\begin{abstract}
:
Many studies in the fields of Law, Sociology and Management point out the transformation of subordination in the employment relation. This transformation of subordination is often explained by the triangulation of the traditionally bilateral employment relation between employer and employees, due in large part to the intrusion of clients or their representatives in the operational and organizational conditions of work, without necessarily distinguishing between the various types of clients, nor between the reality and the rhetoric of the role and the weight of the client. The objective of this paper is 1) to propose a classification of the triangular situations between employer, employees and clients based on the power concept and 2) to analyse the impacts of clients on work conditions and employment relations.
\end{abstract}

Key words: client / labour relation / power / case studies / regulation

The intrusion of clients transforms the traditionally bilateral employment relation between employers and employees into a triangular relation. This intrusion is favored by the development of supply chains and subcontracting networks (Baudry and Gindis, 2004; Author 
C), and by strategies of co-operation (Collins and Doorley, 1991; Dyer, 1996), that create close ties between companies and enable some of them to influence the others. Beyond these particular cases, organizations pay an increased attention to their clients (Lengnick-Hall, 1996; Hartline, Maxham, McKee, 2000). While influencing and controlling the way how the goods and services they acquire are conceived and produced, clients transform the internal organisation and thus the working conditions in the relevant companies producing those goods and services (Rorive, 2005). Sometimes, clients directly interact with the employees of these companies, submitting thus the latter to two different hierarchies, the one of their employer and the one of the client.

Several studies in different disciplines have mentioned this triangulation of labour relations and analysed its consequences on human resources management (Cardy, Gove, DeMatteo, 2000; Korczynski, 2002; Rubery, 2004), on working conditions (Korczynski, 2001) and on social regulation in continental Europe (Supiot, 2001).. Only few researchers, however, analyse the diversity of the situations corresponding to this broad phenomenon. Indeed, the employee does not necessarily suffer from an increased subordination, the client does not always dominate the triangular relation, and the employer still keeps some specific powers. A detailed study of the impact of the triangulation on concrete working situations is thus useful to understand the complex effects of the triangulation of labour relations.

This article suggests a new reading of the triangulation of labour relations showing the diversity of situations between the three actors and the way the subordination is more or less transformed. This article is structured in two parts. The first section replaces the triangulation implied by the intrusion of client in its institutional and legal framework. The article is based on observations of triangular situations in two countries with similar legal and economic backgrounds: France and Belgium. To understand the challenges of the triangulation, it is important to present the legal framework of the work relation in these countries, and in 
particular the central role of the concept of subordination that may or may not be transformed by the triangulation. In the second section, we establish a classification of the different triangular working situations. This classification is based on empirical researches made in France and Belgium by two research teams ${ }^{1}$ between 2001 and 2005 on companies in diverse sectors that were strongly committed to customer relations and presenting various degrees of permeability in terms of client influence. The data for the company studies were generated by three techniques: recorded semi-directive interviews with managers, employees and their representatives; direct observations of work situations; and analysis of various documents edited by companies and worker' representatives. The data collected were supplemented and enriched by meetings between actors from some of the companies who had been confronted with the same type of situations. Several situations, considered as ideal type, have been selected by the researchers to find out a typology of triangulation situations. For each of these situations, we analyse the way the work, the employment and the subordination are or are not transformed. This classification of triangular work situations may be useful also for the analysis of other European countries. Indeed, despite of many differences in the legal contexts, the concept of subordination may be considered as one of the common features of labour law.

\section{The institutional and analytical frameworks of the relations between Employers, Employees, and Clients}

The intervention of clients in the employment relation creates a relational triangle between three different actors linked to each other through different kinds of relations. To analyse the different configurations of the triangulation, we use the sociological concept of power that helps to qualify the relations of influence between the three actors involved. We emphasize on the links between this sociological concept and the legal concept of subordination that 
describes the relation between the employer and the worker. The combination of both concepts enables us to establish a classification of the different triangular work situations.

\section{The relational triangle and its institutional framework}

The client's intervention in the employment relation (defined as the relation between employer and employee) can take different forms depending on the nature of the economic relations between the employer and the client and on the nature of the client who may be either an individual or a company. However, whatever be its form, the client's intervention transforms the traditionally bilateral labour relation into a triangle composed of the employer, the employee and the client.

Of course, these three actors are symbolic figures and some of them may correspond either to individuals or to organisations. This distinction between individual and collective actors is important, but we will show that it does not modify our analysis of the nature of the relations between the three actors, nor the way they are or not regulated by law. We suggest thus to build our analysis of the triangulation on the relations between the three actors (the sides of the triangle) rather than on the actors themselves (the points of the triangle). Consequently, we introduce the idea of a relational triangle as illustrated by figure 1 built of three different relations:

[Insert Figure 1 here - see p. 29]

By employment relation we qualify the relation between the employer and the employee. The manager will be considered in the analysis alternatively as an agent of the employer or as an individual actor defending his or her own interests and with the ability to intervene between the three actors. 
What we call the business relation exists between the employer (a company or an organisation) and its client (another organisation, a group of individuals or an individual).

The service relation is established, directly or indirectly, between the employee and the client. This relation does not only relate to the agents in direct liaison with the clients, but also to the employees who indirectly work for the client (Korczynski, 2004). For this reason, this qualification applies at the same time to service activities and to industrial activities.

In France and in Belgium, each of the three relations is subjected to a different legal regulation. The regulation of employment relations is based on the existence of a legal subordination between the employer and the employees. Characterised through the possibility for the employer to give directives to the worker, to control their execution and to sanction their non-respect, this subordination justifies the employer's use of disciplinary and managerial power, and in exchange grants the employees social protections and guarantees stated in labour law norms, be they imposed by the State or negotiated between the social partners (Gérard \& al., 1996). This model applies both to fixed-term and indefinite contracts of employment. If the employment relation is subjected to the norms of the labour law, the business relation is governed either by commercial law for the client companies, or by consumer law for individual clients. Consumer law- like labour law - is based on the observation of a de facto inequality between the two parties to the relation and endeavours to compensate this by protecting the client, considered as the weaker entity of the business relation. By contrast, commercial law maintains the principle of the equality of the two parties and generally disregards the de facto power relation between the company and its clients. It corresponds to a weak public regulation that grants significant weight to the autonomy of the parties. Lastly, the service relation between employees and clients is, most of time, governed by the general principles of contract or tort law without any specific protection for the employee. In particular, employees whose employers are strongly dependant on another 
company may in principle not rely to any liability of the latter. In certain sectors, however, European labour law has introduced provisions that take into account the service relation to impose some legal obligations to the client to protect the workers. For example, the Directive 92/57/EEC of 24 June 1992 on temporary or mobile construction sites makes the client coresponsible with the employer for assessing the risks to safety and health and imposes the appointment of a health and safety co-ordinator.

The intervention of the client and the associated triangulation of labour relations lead to question the regulation of the employment relation and of the service relation because both the employer and the client can have influence on the employee. Legal researches point out the potential risks for the workers' guarantees and for the principles of social regulation (Supiot, 2001; Chauchard and Hardy-Dubernet, 2003; Castel, 1995). This problem is not limited to France and Belgium, insofar as labour law and social regulation have more largely become under pressure in the context of more complex labour relations. In his report on the future of labour law, Supiot (2001) suggests thus to the European Union to change the foundations of social regulation. Rather than to link social protection to the existence of a contract of employment and thus, at least in France and in Belgium, to the existence of a legal subordination, the European Union should foster a labour law based on the working situation and the person of the worker. Such a reform would enlarge the legal protections to those persons working in situations where the legal subordination is limited or hardly to prove, but who clearly need protection, like some independent workers for example. It would also allow making the clients co-responsible with the legal employer for the social conditions of the workers, without having to prove that the client has completely replaced the employer in the exercise of subordination. However, although the limits of a social regulation exclusively based on legal subordination have been shown in many studies, the policy makers both in France and at the European Union level have only made minor progress in this field. 
But beyond this legal analysis, the reality and the diversity of the influence between the three actors have been more rarely studied. Indeed, it is necessary to highlight the diversity of the nature of these relations through the analysis of concrete work situations. Does the triangulation always lead to an increased subordination of the employee submitted not only to the employer but also to the client? Or does it lead to a simple change of the dominant actor in the subordination, the employer being progressively replaced by the client? To what extent does the client really interferes in the way the work is performed? To highlight this diversity and to analyse the relations between the three actors, we suggest bringing in the concept of power.

\section{The contribution of the concept of power to analyse the relational triangle}

How analysing globally the different relations of the triangle? Our approach was the following. The employment relation is characterised from a legal point of view by a subordination relation. This relation is indeed a de jure and de facto power relation because the employer exerts formally and in practice an authority on the employee. Then why not analyse the other relations of the triangle with the concept of power which is mobilised by several disciplines. Indeed, different disciplines, such as law, management and organisation sociology do use the power concept to analyse the relations between the economic agents.

For labour lawyers, the power relations between the employer and the employee constitute the condition for the existence of a contract of employment and the justification of the intervention of the legislator (Dockès, 2004). In a similar vein, organisation sociologists mobilise the concept of power to highlight the inequality between employers and employees (Barratt, 2002; Borzeix, 2003) or to illustrate how the employee may rely on specific skills or strategic information to exert some form of counter power on his employer (Crozier and Friedberg, 1980). Finally, the management literature frequently refers to the concept of power 
based on the control of resources to analyse the business relation between a company and its clients (Pfeffer and Salancik, 1978; Casciaro and Piskorski, 2005).

However the way to define the power in these different disciplines is various (Avelino, 2006) and these different disciplines do not analyse simultaneously the power relations between the three actors. In this article, we suggest using the notion of power as a common conceptual framework to analyse the employment relation between employers and employees, the business relation between companies and client as well as the service relation between clients and employees.

We adopt a "one dimensional view of power" (Lukes, 2005) to understand the relations in the triangle, considering power as the capacity to obtain behaviour from others that they would not have exhibited. Insofar as it is defined in relation to others, power is exerted within the framework of a "social relation" marked by reciprocity (Weber, 1978). Moreover, the use of power depends on the resources of which the actors dispose and the extent to which they can be used against others (Hardy, 1985). These resources are related to the context and to the characteristics of the person. A person capable of controlling an uncertainty (a behaviour, an event) or possessing a particular expertise will be likely to exert power over others (Crozier and Friedberg, 1980; Mintzberg, 1983). This conception of power centred on the relationship and the resources can be used to analyse the three kinds of relations in the triangle.

In law as in other social sciences, the bilateral relation between the employer and the employee may be analysed as a power relation based on the legitimate authority conferred by the employer's status (Weber, 1978; Dockès, 2004). In return, the employer will take into account the qualifications or skills of the employee as well as his or her expectations expressed individually or collectively. The power relation between employer and employee is thus a reciprocal relation of exchange, but it is by definition, an asymmetric one (Crozier and 
Friedberg, 1980). It is also a relation where competencies of each part are recognised: managerial competencies for the employer and technical expertise (linked to information, knowledge, skills, traits) for the employee.

The relation between a company (represented by the employer) and its clients can also be analysed in terms of power. As highlighted by the theories of resource dependence (Pfeffer and Salancik, 1978; Frazier, 1984; Christensen and Bower, 1996), the company (supplier) can exert power over its clients if it is able to create a situation of dependence. This dependence is linked to the specificity and the scarcity of the resources held by the company, to the low substitutability of the products or services provided, and to the high cost involved in changing suppliers (Klein, Crawford, Alchian, 1978; Barney, 1991). Conversely, the client can exert power over the supplier if they are able to create a form of dependence, for example by clauses for contract termination or by controlling the competition.

Lastly, the relational conception of power is also relevant in the analysis of the relations between the employee and the client. Research carried out on employees in direct liaison with the clients indeed shows that the client is able to exert direct power over the employee, through his or her requirements, because of the situation of competition, because of a superior knowledge of the nature and specificities of the goods or services provided, or because he or she can evaluate the quality of the service (Gadrey, 1994; Jeantet, 2003). Conversely, an employee in direct contact with a client can exert power over the latter due to his or her expertise regarding the characteristics of the goods and the realization of the service provided, the control of the temporality of this service, and to the ability to reformulate the client's demand.

Even if the three relations are not of the same nature, this conception of power centred on relationship and sources of power thus constitutes a relevant base to analyse the bilateral relations between employers and employees, between companies and clients and 
between employees and clients. They also make it possible to highlight the triangulation between these three actors and the consequences for the subordination.

\section{The diverse configurations of the relational triangle}

Considering the reciprocal relations of power between the three actors, we can figure out several situations where one or two actors can exert power (dominant position) over the other (dominated position) or the two others. The range of different possibilities is illustrated in Figure 2.

[Insert Figure 2 here - see p. 29]

Thus, for example the employer can exert power over both their employees and their clients (situation 1). Another alternative is that the employer and the client both exert joint power over the employee (situation 3). Six situations can thus identified. They are considered as "ideal types" in the Weberian mode, that is to say that based on real situations observed during investigations of companies or actors' testimonies, relational configurations are constructed whose features are accentuated to facilitate their comprehension. Several of these ideal typical situations can thus be found in the same company, corresponding to different products or services.

The range of the diverse situations shows the way the employment relations based on the subordination can be more or less challenged. If, due to the intrusion of the clients, the employers no longer exert, or are no longer the sole entities to exert a de facto power on the employees, their qualification as employers must be questioned. Indeed, labour law considers that what prevails are the actual work situations and not the legal qualification determined by the actors (Jeammaud, 2001). Of course, the judge may sanction situations where the formal employer is not the one to whom the employee is subordinated in reality. But this does not 
offer a solution for the numerous situations where the power relations are more complex and where the interference of the client is subtler, more sporadic and sometimes concomitant to the one of the employer. Moreover, even in situations where the de facto power is clearly in the hands of a single client, the employees rarely go to the courts to ask for the latter being considered as their employer. This model of analysis thus offers the means to specify the diversity of work and employment situations in companies and to examine if and in what way they translate into a transformation or a reconsideration of the subordination.

For each of these situations, it is possible to analyse a variety of issues: (1) the way in which each relation evolves according to the organizational configuration by defining the actor or actors and the relation that dominate the others; (2) the effects on the nature of the work performed by the employee (nature of the skills, degree of autonomy, person in charge of evaluating the work, the working conditions); (3) the effects on the employment relation (stability of the relation, conditions of remuneration, employment statute); and (4) the role of management (support of a specific actor - employer or employee -, mediator between two actors, or passive behaviour).

\section{Diversity of the relational situations and their impact on subordination}

Findings from several research projects made since the beginning of 2000's on the evolution of work relationships in France and Belgium illustrate six work situations corresponding to different power relations between employers, employees and clients as illustrated in figure 2 . The nature of client can be different in each case, but it has no matter on the substance of analysis because we try to qualify each time the power relation and its resources between the actors. The six cases are presented below in three categories because the analysis revealed that some maintain the legal subordination between the employer and the employee (2.1.), some displace it (2.2.) and others dilute it (2.3.). 


\section{Situations where the subordination is maintained}

The first two situations correspond to the preservation of the subordination between employer and employee. In spite of the intrusion of the client, it is the employment relation that structures the relationships between the three actors.

\section{Situation 1:}

In the TELTIC case $^{2}$, the employee remains subordinated to the authority of the employer who manages to limit the interference of the client. TELTIC is a team a multi-client call centre (LeaderCall) has dedicated to one of its large accounts, an IT manufacturer. The work conditions and organization of this team vary from other teams according to the clients' demands, their degree of intervention and the type of contract concluded. TELTIC team, is in charge of the fulfilment of a subcontracting contract with an IT manufacturer who delegates all their customer service management to the call centre. This client acknowledges the expertise of the call centre with whom they have been doing business for almost ten years. Although the quality standards required are very high, the client allocates a great deal of operational autonomy to the members of the designated team who are allowed to make decisions without prior warning or authorisation necessary (honouring the guarantee, compensatory offers, etc). . It is the management of the call centre that monitors the quality of the service through various tools (call recording, side by side monitoring, etc). However, with their high level both technical and interpersonal skills, the employees are relatively autonomous in the execution of their job. The client is not present at the call centre and only monitors the quality of the service provided through the intermediary of some key performance indicators.

The trust that characterizes the business relation between LeaderCall and its client keeps the latter from intervening directly in the management of the TELTIC team. While 
working exclusively for one client, the employees still have a "traditional" employment relation and are subordinated to their legal employer. The employer protects the employee from a service relation dominated by the client. He limits the client interference and retains control of work regulation and supervision. The business relation is balanced, or even slightly dominated by the supplier, due to the power conferred by the possession of an acknowledged expertise in management of consumer relations, the significant information regarding consumer behaviour and the needs of the product users. LeaderCall provides a service whose added value is appreciated and sought by the client. This service is built on the development of the agents' skills. The employment conditions are good for the sector, the employees benefiting from open-ended contracts, job training and internal career mobility. Quality requirements imposed by the clients force the call centre to adopt a strict standardization of work procedures, direct supervision and constant quality control of the agents' work, which results in the maintenance of a tight relationship of subordination.

\section{Situation 2:}

In the Districolis case, the employment relation is even more dominant than in the LeaderCall Case: the client is the weak party both in the business relation and in the service relation. Districolis is a subsidiary of a public postal operator created in 2000 to ensure the distribution of parcels to consumers. The shipping clients are mail order companies, SMEs, artisans/store owners or private individuals. There is little competition from private operators in his sector, still subject to the public utility obligations. This obligation has two consequences: first, the company must deliver all parcels under $20 \mathrm{~kg}$ to any individual client regardless of the associated costs; secondly, this obligation authorizes the hiring of employees under the civil servant statute. Indeed, the majority of the people working in the company are civil servants or employees recruited under open-ended contracts having a certain job security and good 
employment conditions. The work of the agents primarily consists of sorting the parcels by distribution zones and delivering them to the receiving client. The task of sorting is done manually but requires the knowledge of the distribution route organization, which results in the specialization of agents to specific distribution zones. In addition, the agents are autonomous in their distribution routes. The on-site management controls the quality based on client complaints (sending or receiving). Lastly, there are strong unions that are able to exert pressure on company management.

In this case, the employment relation remains dominant compared to the service and business relations. The service relation is reduced to a minimum since, due to the fact that most parcels are delivered to a mailbox, the employee seldom meets the clients (the recipients). Client (recipient but more sender) complaints are made directly to the company who then relays them to the employee. It should be noted that complaints are the only way for the client to express their dissatisfaction given that there are few alternatives due to the lack of competition. Conversely, the employment relation is balanced, since the employees have two sources of power: their specific knowledge relative to the distribution network and their ability to lead collective actions co-ordinated through the trade unions. In this situation, the employees' representatives play an important role and contribute to compensate the subordination. The balance in the power relation particularly manifests itself through stable employment reinforced by the quasi-monopoly of the company and through good working conditions defined in the civil servant statute and in collective agreements.

The two above-mentioned situations correspond to a weak or even inexistent influence of the client on the subordination. These two situations correspond to the traditional model of the employment relation, in which the middle management concretises the subordination. The human resources management relies on "internal labour markets" (Doeringer \& Piore, 1971) based on collective norms negotiated with the employees' 
representatives and guaranteeing a certain employment security. This is a major difference with the following situations.

\section{Situations where the subordination is displaced}

In situations 3 and 4 , the subordination between employer and employee is profoundly modified by the intrusion of the client and the business relation dominates the triangle.

\section{Situation 3:}

In the Netto case, the triangle is clearly dominated by the client. Drawing from its power in the business relation, the client exerts such an influence on the employee that the subordination shifts in their favour to the detriment of the employer. In this industrial cleaning and facility management company, the employees spend all their working hours at the clients' sites. If the size of the facility warrants it, the cleaning teams are led by a team leader in charge of supervising the work and verifying the application of the extremely precise cleaning procedures established by management. The team leader is in charge of assigning tasks to the various employees based on the employer's specifications (cleaning procedures) as well as those of the user firm. In the case of smaller job sites, the employees are integrated into the clients' work teams. The employees must respect the work procedures and a "mobile" team leader regularly visits the job site to ensure the conformity of the work to the established procedures and verifies that the terms of the contract are being respected. Normally, the nature of the tasks to be accomplished is specified in the commercial contract linking the employer to the user firm. In reality, the clients' foremen frequently ask the cleaning staff to carry out tasks not specified in the contract. The user firm is also involved in employee selection as well as their evaluation. It determines the employees' work schedules and times, 
along with the employer. The client's involvement is more limited in regards to training, particularly in the area of work safety. Often, the cleaning staff have progressively developed a strong loyalty to the user firm whose logo and uniform they wear. When a problem arises, they rather turn to the employees' representatives of the user firm than to their own representatives.

The business relation between the client and the supplier of the cleaning services dominates the relationships between the various actors of this triangle. The asymmetry that characterizes this relation (abundance of cleaning offers, logic of domination by costs, competition, interchangeability of the cleaning staff, etc.) places the client in a position of power with regards to the employer who resists poorly to the client's intrusion and to the employees who possess neither strategic resources nor specific skills. The subordination between the employee and their employer weakens and shifts to the client who exerts the authority over the employee without an intermediary and dictates the majority of the working conditions (work schedule, content of tasks, work pace, special requests, etc.). The quality of the work is monitored and assessed by the client, even if the employer also verifies the conformity of the services to the procedures and client's demands. The employer does not have a specific human resource management policy towards the low skilled and easily replaceable employees. The employment relation is subordinated to the business relation: a rupture of the second being likely to cause a break of the first. The employment instability that characterizes this situation is such that labour law protects the employees. The Community directive on company transfers dated March 12, 2001 imposes that in the event of a change of supplier the new provider must keep on the employees assigned to the facility and maintain their individual employment contracts. However, this legal regulation does not compensate for the high level of pressure on the employment statutes in this sector. 
Situation 4:

In the forth situation, the business relation still dominates the service and the employment relation, but the employer shares the power with the client. Infoline is another work team of LeaderCall Call center. This team of telephone operators is assigned to a contract involving a regional public administration. The latter decided to outsource the management of their citizens' initial inquiry telephone service but keeps close control over this sensitive activity. The contract with the public administration leaves minimal room to manoeuvre. Civil servants assigned to the call centre by the government manage and monitor the execution of the contract by the teleoperators of Infoline. They ensure the operational management of the project and train the telephone operators on the specific characteristics of the public utility departments involved. They collaborate with the on-site call centre hierarchy, whose intervention is limited to the financial management of the contract, and to the articulation of the operations with the various call centre support services (Information technology, Quality Development, management control). The telephone operators of the Infoline team are therefore subject to a double hierarchy, that of the contractor and that of LeaderCall, their employer. The work is very standardized: the agents, generally low skilled employees, are required to conform to scripts developed by the client. The latter frequently monitors the work quality (listening to recorded calls, side by side monitoring, review of performance indicators, etc).

In this team, the employment relation is strongly influenced by the interference of the client who intervenes alongside the employer in the prescription and control of the work. While the business relation dominates the triangle, it however appears more balanced than in the third case. The outsourced activity assumes a strategic character, the supplier proposes services that are differentiated and organized in an "a la carte" manner, which enables them to resist a client who does not completely delegate the activity. For various reasons (lack of 
trust, innovations in outsourcing procedures, possession of know-how, etc), the client intervenes in the employment relation, but the marketable assets that favour the supplier prevent inequality in the relation. The employee, who has few specific skills, faces a double hierarchy and is subordinated to both the employer and the client. The working conditions are the result of a compromise between the client's requests and desires (opening hours of the telephone lines, number of calls treated, call distribution, etc.) and the operational procedures put in place by the call centre. However, the frequent presence of the client at the call centre increases the pressure on the agents and on the work pace which can lead the employee to break the employment relation. This risk results in a more significant turnover rate in this team than for example in the TELTIC team. However, with the establishment of a durable business relation, stability sets in, the relations evolve, and some agents even consider continuing their careers as employees of the client.

Situations 3 and 4 highlight a total or partial displacement of the subordination from the employer to the client. They illustrate the fading role of the management as an intermediary between the client and the employee. The LeaderCall managers dealing with the Infoline contract share the power with the client which may either create a difficulty for the employees who sometimes have to arbitrate between contradicting directives or, on the contrary, establish a space of freedom providing them with local power (Crozier and Friedberg 1980). In the case of a completely inexistent role of the management as in the Netto case, the managers may lose their legitimacy and their credibility in the eyes of the employees, in particular if the situation concerns all contracts or if it persists.

If the power is displaced in the hands of the client, the human resources management is completely or partially outsourced. In the Netto case, the recruitment and the evaluation of the employees as well as the definition of working time and collective relations are completely in the hands of the managers of the client. If the power is shared, only some aspects of the 
human resources management are affected: the evaluation of the employees directly linked to the directives transmitted and to the required skills, the training that may be focussed on the needs of the client, and the management of the careers that may favour the transfer of certain employees to the client.

\section{Situations where the subordination is diluted}

Situations 5 and 6 illustrate a dilution of the subordination between employer and employee. The subordination fades because the employee exerts a de facto power, alone or in partnership with the client. In these situations, the service relation dominates the triangle.

\section{Situation 5:}

In the Comptapro case, the employee and the client create an alliance to exert a power on the employer. Comptapro responds to the shortage of the Luxembourg labour market by providing accounting and financial personnel for the back office activities of banking houses (account management, transaction follow up, reporting, title management, etc.). In theory, the missions are short term and vary from 4 to 6 months in length. In the event of an extension, Comptapro tries to replace the persons assigned to the mission in order to avoid any significant attachment to the client. Comptapro requires that their employees conform and adapt to the client's organization and fulfil all requests or regulations emanating from the client but does not directly supervise them. The work schedules, the hours worked, the days off, and the working conditions generally vary from one mission to another, as well as the level of autonomy allotted to the accountants Comptapro's administrative staff is minimal: a director assisted by a manager and a secretary. The client strongly intervenes in Comptapro's human resource management. They select the employees on the basis of CVs sent by the 
Comptapro, and they are involved in the training of the employees who are evaluated according to their own standards as well as to those defined by Comptapro. Comptapro's management uses client feedback to establish the objectives to be attained by the accountants the following year as well as any suggested trainings. In order to retain their employees, who are highly mobile given the shortage of employees in the Luxembourg market, Comptapro has set up a career management policy.

The service relation dominates the triangle, since the employees possess a strategic resource enabling them to evolve into a relationship of mutual dependence with the client. While the skills that the employees possess are common, their scarcity and direct correspondence to the clients' requirements enable them to exert a strong countervailing power over their employer. The employer is thus eclipsed by the collusion of interests between the employee and the client. The company's desire to be flexible and to meet the demands of a changing market renders it extremely frail and easily permeable in regards to external influences. The Comptapro management has only a weak influence over their employees and its principal role is limited to ongoing training. The complicity stemming from the proximity between the employee and the client is sometimes opposed to the employer whose interests do not necessarily correspond to those of the client. The business relation is symmetrical since the labour market situation renders the services offered by Comptrasec, invaluable in the eyes of the client despite an extremely narrow core business. Since it involves a rare resource, the work done represents a valuable commodity for both the client and the employer. The employment relation is stable and the employees are protected both from the risks of the transactions: the duration of the employment contracts is in no way related to the duration of the commercial contracts. The risk of employment instability shifts to the employer who at any moment can be confronted with "freelance" behaviours or with clients or the labour market hiring away. 


\section{Situation 6:}

The sixth situation is very rare: In the ITC company, the employee dominates alone the triangle and exerts power over the other two actors. ITC, a multinational company works in several areas of the IT market (software, hardware, equipment, systems and consulting) and develops a strategy of differentiation and innovation enhancing their competitiveness. Their consulting and service activities make up a significant share of their business. This is a strategic division for ITC because it distinguishes them from their primary competitors and enhances their brand name status and reputation. The company primarily assigns long-term consultants to clients for the management of IT projects. The company rarely interferes in the consultants' work and grants them a great deal of freedom to manage their mission (setting of schedules, definition of tasks, monitoring of performance indicators, etc.). The consultants are however encouraged to respect a methodological framework created by ITC. In theory, the work organization is based on a balance between the procedures set out by this framework and the autonomy of the consultants. Each consultant is responsible for the respect of the procedures, determines the margin of manoeuvrability and develops the rigour and the self-discipline necessary for the mission. Neither the client nor the employer defines the working conditions; it is up to the consultants to determine their own hours and work schedules based on the specifications and constraints of their mission. The consultants negotiate their employment conditions with their employer according to the specificity or the difficulty of the mission and their marketable personal resources (cutting-edge skills, unique expertise, etc.).

This last situation is characteristic of employment relations marked by a high level of autonomy for employees who to some extent "impose themselves" on their employer and their client due to a rare level of qualification and expertise. As the employees have a resource that is strategic for the employer (who uses this as their primary selling point) and for the client (on which the success of their IT business project rests) they control the transaction 
between the employer and the client. The business relation is thus completely subordinate to the service relation. If the latter dominates the relationships of the triangle, it is however asymmetrical and in favour of the employee whose skills are highly specific and adequately meet the client's needs. The client calls on a consultant to exercise a trade of which they know little and are not able to control. They do not intervene in the monitoring or the prescription of the work of the consultants, who are allotted full autonomy. The subordination is greatly weakened given that the employee is solely responsible for the execution of the mission as well as the establishment of the conditions involved. The employer resists the external influences and the management gives methodological support to the consultants. Given the strong value of their work for both the employer and the client, the employees are thus able to negotiate their employment conditions in a relationship that they can terminate at any time, provided that the demand continues to be favourable in the job market.

As the subordination is diluted, the role of the management is fading, or even completely inexistent. Sometimes, the employee may enter into a dialogue with the managers, but both parties are on an equal footing. In both situations, the human resources management takes specific forms. It is based on the principles of the market (Storper and Salais, 1997), insofar as all aspects of human resources (evaluation, remuneration, training) are negotiated between the employee and the employer. This negotiation is possible because of the power the employee shares with the client or exerts alone. The negotiation takes place each time the employee and the employer agree on the provision of a new service or the production of a new good for the client. The human resources management is individualised, insofar as the negotiation takes place between two individuals (the employee and the employer). In its extreme version (situation 6), the human resources management is almost inexistent as the employee manages his own resources. These working situations are far from being 
generalised, but they illustrate a tendency to more individualised employment relations that challenge the social regulation by labour law.

\section{Conclusion}

The model proposed here seeks to account for the diversity and the complexity of the work and employment situations created by the intrusion of the client. The concept of power makes it possible to better understand for each situation up to what point the client, the employer or the employee exert alternatively or jointly an influence on the other actors. These different situations of triangulation correspond to different roles of the middle management and to different forms of management, confirming thus the strong impact of the context on the management models (Pichault and Schoenaers, 2003).

This model built around six static ideal-typical situations can also be considered from a dynamic perspective. Indeed, when the relational or environmental contexts change, the triangular configuration can alter in favour of one or two actors. The loss of a monopolistic situation can lead the employer to modify their behaviour with respect to the client and reinforce the triangulation of the work relationships. The obsolescence of the skills of a employee dominating the triangle by using the service relation can result in a reversal of the power relationships and subject him either to a relation of subordination or to the interference of the client.

By putting forward the complexity, the diversity and the dynamics of the triangulation of the work situations, our analysis questions the relevance of a universal and homogeneous model of regulation to embrace the whole scope of the situations of subordination (Borzeix, 2003). One can consider that the current model founded on subordination has an answer to the challenges posed by the intrusion of clients in the bilateral relation of employment, insofar 
as the courts can use their de facto power to identify the real employer of the employees and to distinguish between "real" and "pseudo" employees. Such a decision supposes, however, that only one actor exerts the de facto power in a permanent manner, excluding thus a certain number of situations presented in our classification, and that the dominated actor goes to court which is very rare. These work situations are thus regulated in a way that is not satisfying, because the exercise of the de facto power is not compensated by social guarantees, as is the aim of labour law.

It thus seems important to think about the new principles that may underpin the regulation of work situations, taking as a basis the debates at the roots of labour law that had opposed those who wanted to limit its scope to situations characterized by a legal subordination to those who wanted to extend it to any kind of economic subordination (Revet, 1992). This debate is linked to the work of several researchers questioning the current model of regulation and proposing a legal regulation that would not be limited to the relations of employment but include all forms of professional activity (Supiot, 2001). But the great diversity, the increasing complexity of field situations and the dynamic of situations questions even the relevance of the emergence of a single and universal model intended to replace the existing one. A new perspective might thus emerge and constitute a future perspective for research: it would be necessary to explore how to revise current regulation that is primarily substantial, insofar as it defines the contents of social norms, towards a more procedural regulation, while continuing to guarantee the respect of the fundamental social rights (Ladeur, 1996). In this perspective, corporate social responsibility may complement the existing social regulation and constitute a possible answer to the diversity of the situations of triangulation (Sobczak, Rorive and Havard, 2006). 


\section{End-notes}

${ }^{1}$ A Belgian team, the LENTIC (Laboratory for the study of new technologies, innovations, and change - www.lentic.be) and a French team from Audencia Nantes School of Management (www.audencia.com).

${ }^{2}$ In this case, the analysis is limited to the relationships between the teleoperators and the client of the call center even if the teleoperators are also in direct relation with the final customers (the client of the client).

\section{References}

Avelino, F. (2006) 'Reconceptualising Power', Berlin Conference on the Human Dimensions of Global Environmental Change "Resource Policies: Effectiveness, Efficiency, and Equity", 17-18 November.

Barney, J.B. (1991) 'Firm resources and sustained competitive advantage', Journal of Management 17(1): 99-120.

Barratt, E. (2002) 'Foucault, Foucauldianism and human resource management', Personnel Review 31(2): 189-204.

Baudry, B. and Gindis, D. (2004) 'Specificity of the network-firm and the boundaries of the firm', in I.D. Salavrakos (ed.) Aspects of globalisation, regionalisation and business, Athens Institute for Education and Research (ATINER) : London, pp. 273-288.

Borzeix, A. (2003) 'Autonomie et contrôle à l'épreuve d'une rationalité externe', in G. De Terssac (ed.) La théorie de la régulation sociale de Jean-Daniel Reynaud - Débats et prolongements, pp.197-206, Paris: La Découverte. 
Cardy, R.L., Gove S., DeMatteo, J. (2000) 'Dynamic and customer-oriented workplaces Implications for HRM practice and research', Journal of Quality Management 5: 159-186.

Casciaro, T. and Piskorrski, J. (2005) Power Imbalance, Mutual Dependence, and Constraint Absorption: A Closer Look at Resource Dependence Theory', Administrative Science Quarterly 50(2): 167-199.

Castel, R. (1995) Les métamorphoses de la question sociale. Une chronique du salariat. Paris : Fayard.

Chauchard, J.-P. and Hardy-Dubernet, A.-C. (eds.) (2003) La subordination dans le travail. Cahier Travail et Emploi, Paris: La Documentation Française.

Christensen, C.M. and Bower J.L. (1996) 'Customer Power, Strategic Investment, and the Failure of Leading Firms', Strategic Management Journal 17(3):197-218.

Collins T.M. and Doorley T.L. (1991) Teaming up for the 90s. A Guide to International Joint Ventures and Strategic Alliances, Homewood: Business One Irwin.

Crozier, M. and Friedberg, E. (1980) Actors and systems: the politics of collective action. Chicago/London: University of Chicago Press.

Dockès, E. (2004) 'Le pouvoir dans les rapports de travail - Essor juridique d'une nuisance économique', Droit Social, 6, 621-628.

Doeringer, P. and Piore, M.J (1971), Internal Labor Market and Manpower Analysis, Heath, Lexington Books.

Dyer, J.H. (1996), "Specialized supplier networks as a source of competitive advantage: evidence from the auto industry ", Strategic Management Journal, 21, 73-99.

Frazier, G.L. (1984) 'The interfirm power-influence process within a market channel', in J.N. Sheth (ed.) Research in marketing, pp.63-91, Greenwich-Connecticut: JAI Press. 
Gadrey, J. (1994) 'Les relations de service et l'analyse du travail des agents', Sociologie du Travail 36(3): 381-389.

Hardy, C. (1985) 'The Nature of Unobstrusive Power', Journal of Management Studies 22(4): 384-399.

Hartline, M.D., Maxham, J.G., McKee, D.O. (2000) 'Corridors of Influence in the Dissemination of Customer-Oriented Strategy to Customer Contact Service Employees', Journal of Marketing 64(2): 35-50.

Jeammaud, A. (2001) 'L'avenir sauvegardé de la qualification de contrat de travail', Droit Social, $3: 227$.

Jeantet, A. (2003) 'A votre service! La relation de service comme rapport social', Sociologie du Travail 45(2): 191-209.

Klein, B., Crawford, R.G., Alchian, A.A. (1978) 'Vertical Integration, Appropriable Rents, and the Competitive Contracting Process', Journal of Law and Economics 21(2): 297-326.

Korczynski, M. (2001) 'The contradictions of service work: Call centre as customer-oriented bureaucracy', in A. Sturdy, I. Grugulis, H. Willmott (eds.) Customer Service, Basingstoke: Macmillan/Palgrave, 79-102.

Korczynski, M. (2002) Human Resource Management in Service Work. Basingstoke: Palgrave.

Korczynski, M. (2004) 'Back-Office Service Work: Bureaucracy Challenged?’, Work, Employment \& Society 18(1): 97-114.

Ladeur, K.-H. (1996) Proceduralization and its Use in Post-Modern Legal Theory. European University Institute, Working paper, LAW 96/5, Florence, Italy.

Lengnick-Hall, C.A. (1996) 'Customer Contributions to Quality: A Different View of the Customer-Oriented Firm', The Academy of Management Review 21(3): 791-824. 
Lukes, S. (2005) Power: A Radical View, Basingstoke: Palgrave Macmillan.

Mintzberg, H. (1983) Power in and around organisations. Englewood Cliffs (N.J.): Prentice-Hall.

Pfeffer, J. and Salancik, (1978) The External Control of Organizations: a Resource Dependence Perspective. New York: Harper \& Row.

Pichault, F. and Schoenaers, F. (2003) 'HRM Practices in a Process of Organizational Change. A Contextualist Perspective', Applied Psychology. An International Review 52(1): 120-143.

Revet, T. (1992) La force de travail. Etude juridique. Paris: Litec.

Rorive, B. (2005) 'L'entrprise réseau revisitée: Une tentative d'ordonnancement des nouvelles formes d'organisation', Gérer et comprendre, n 79: 63-75.

Rubery, J., Carroll, M., Cooke, F.L., Grugulis, I., Earnshaw, J. (2004) 'Human Resource Management and the Permeable Organization : The Case of the Multi-Client Call Centre', Journal of Management Studies 41(7): 1199-1222.

Sobczak, A., Rorive, B. and Havard, C. (2006) 'Quel rôle de l’Etat dans la régulation des relations triangulaires de travail ? Le cas du travail intérimaire et des centres d'appel' Paper presented at the MATISSE Conference, Paris, September 2006.

Storper, M. and Salais, R., (1997) Worlds of Production. The Action Frameworks of the. Economy. Cambridge MA: Harvard University Press.

Supiot, A. (ed.) (2001) Beyond Employment. Changes in Work and the Future of Labour in Europe. Oxford: Oxford University Press.

Weber, M. (1978) Economy and Society. Berkeley: University of California Press. 
Figure 1: The triangle of relations

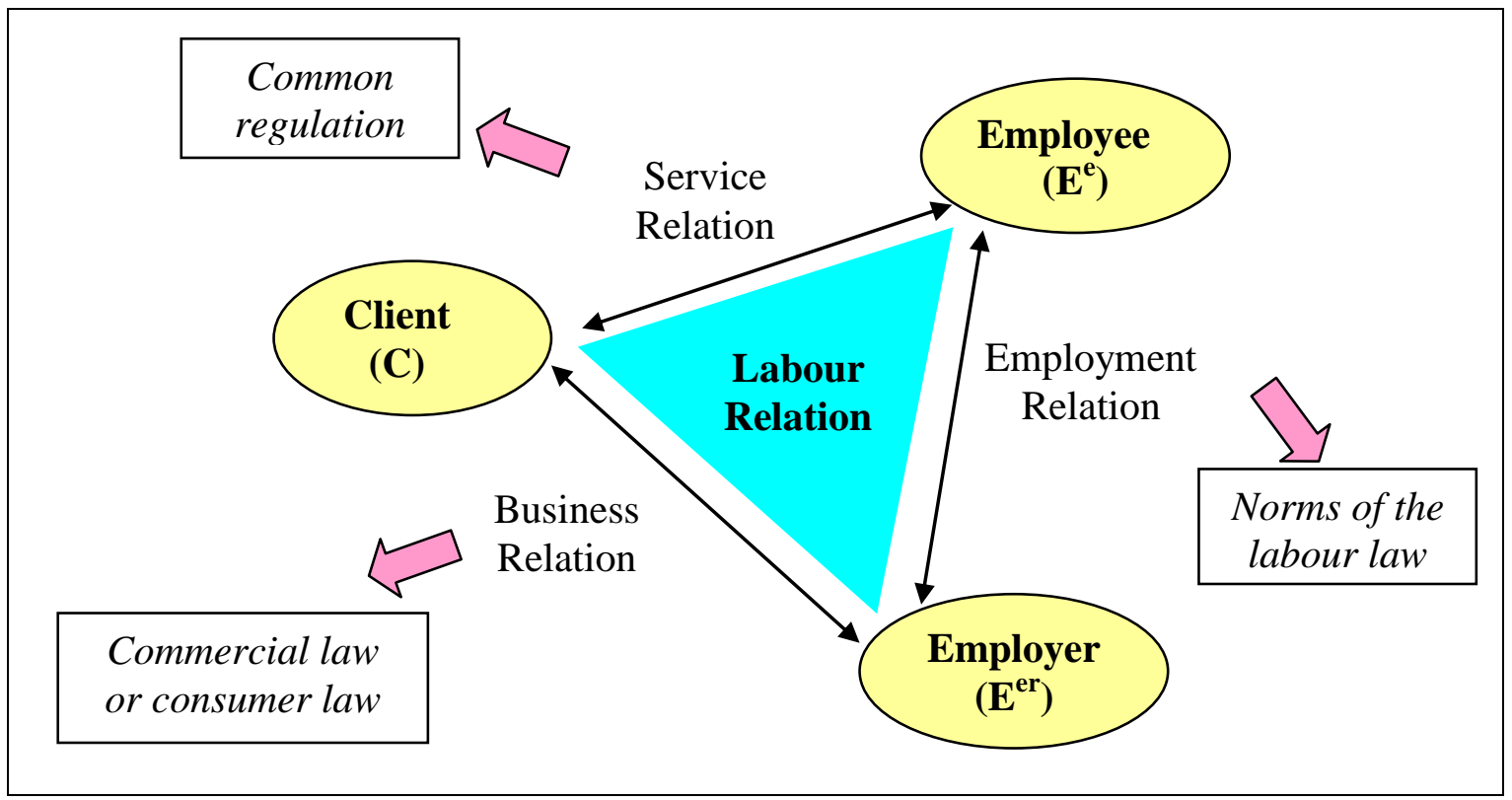

Figure 2: Six triangulation situations

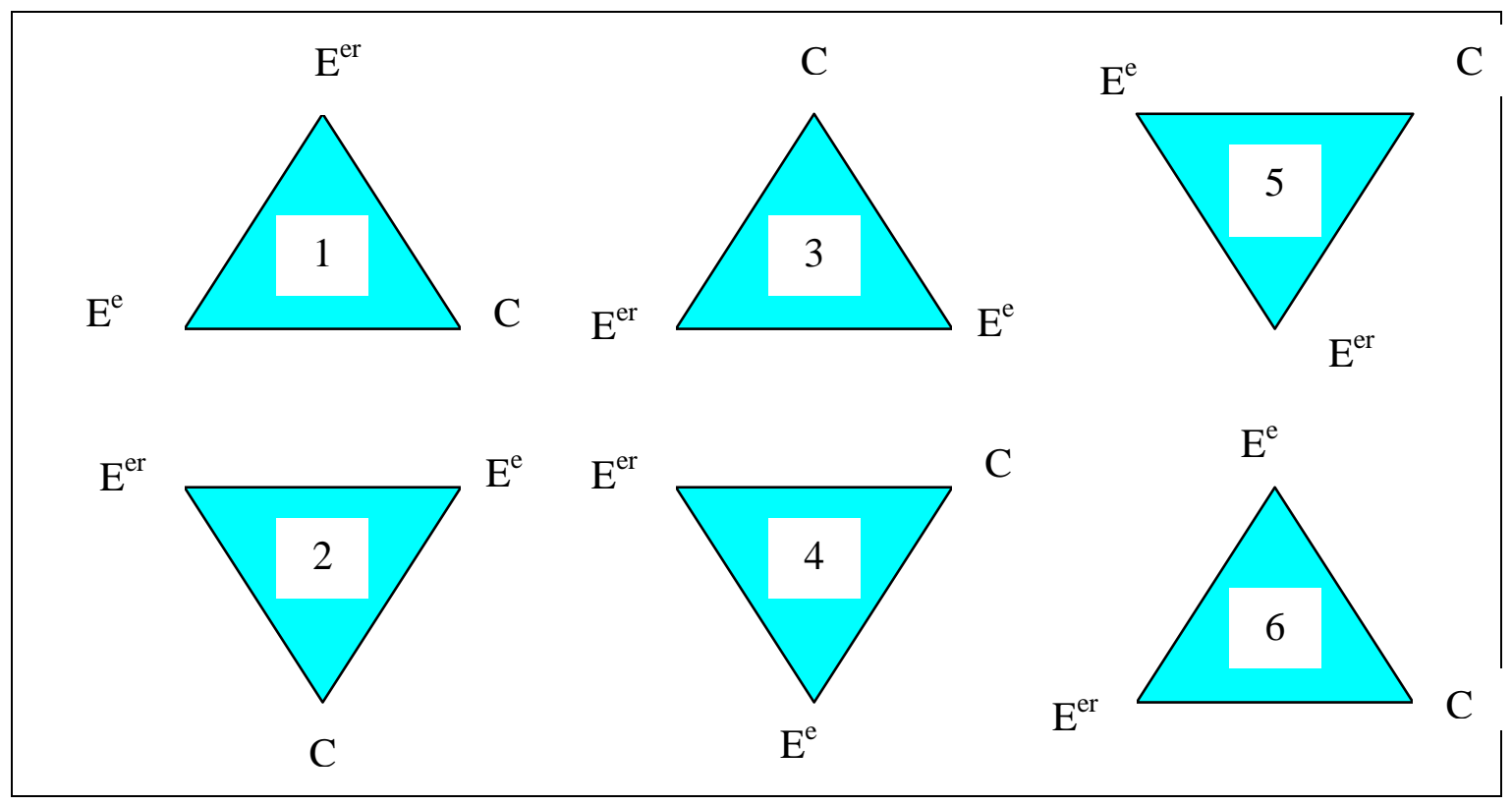

